Pediatr. Res. 14: 968 (1980)

\title{
Letter to the Editor: Serum Salivary and Pancreatic Amylase
}

\author{
ROBERT O. WOLF AND VAN S. HUBBARD
}

Oral and Pharyngeal Development Section, National Institute of Dental Research [R. O. W.], and Pediatric Metabolism Branch, National Institute of Arthritis, Metabolism and Digestive Disease IV. S. H.J, NIH, Bethesda, Maryland, USA

We are grateful to Dr. K. F. McGeeney for calling our attention to his experience that cystic fibrosis patients with pancreatic insufficiency do not exhibit an increase in the salivary amylase contained in their sera. Such an increase would be expected if a compensatory mechanism were in effect as suggested by Davidson et al. (1).

We agree with Dr. McGeeney that most techniques presently used for the assessment of the serum content of salivary and pancreatic amylase leave much to be desired with respect to time, efficiency, and accuracy of quantitation. The inherent vagaries of amylase quantitation have long created difficulties in interpretation of observations from different laboratories. Different techniques may be in part responsible for the varying results reported. It would be of great interest to us to accomplish a comparative method study of the wheat inhibitor method (2) in comparison with our PAGE slice technique (3) and including perhaps a third technique such as chromatography or a cellulose acetate electrophoretic separation with densitometric evaluation.

\section{REFERENCES AND NOTES}

1. Davidson, G. P.. Koheil. A., and Forstner, G. G.: Salivary amylase in cystic fibrosis. A marker of disordered autonomic function. Pediatr. Res., 12: 967 (1978).

2. O'Donnell, M. D., FitzGerald, O., and McGeeney, K. F.: Differential serum amylase determination by use of an inhibitor and design of a routine procedure. Clin. Chem., 23: 560 (1977)

3. Wolf, R. O. Taussig, L. M. Ross, M. E. and Wood, R. E. Quantitative evaluation of serum pancreatic isoamylases in cystic fibrosis. J. Lab. Clin. Med., 87: 164 (1976). 